e-Journal Studi Kelayakan Objek Wisata Alam Monkey Forest (Mandala Wisata Wenara Wana) untuk Pengembangan Ekowisata di Desa Padangtegal, Kecamatan Ubud,

Kabupaten Gianyar Universitas Pendidikan Ganesha Jurusan Pendidikan Hukum dan Ilmu Sosial (Volume x Tahun 2017)

\title{
STUDI KELAYAKAN OBJEK WISATA ALAM MONKEY FOREST (MANDALA WISATA WENARA WANA) UNTUK PENGEMBANGAN EKOWISATA DI DESA PADANGTEGAL, KECAMATAN UBUD, KABUPATEN GIANYAR.
}

\author{
Ni Putu Rahayu Mutiara Dewi, Sutarjo, I Wayan Treman \\ Jurusan Pendidikan Hukum dan IImu Sosial \\ Universitas Pendidikan Ganesha \\ Singaraja, Indonesia
}

email:

\begin{abstract}
Abstrak
Penelitian ini dilaksanakan di objek wisata alam Monkey Forest dengan tujuan 1) Mendeskripsikan potensi ekowisata di Objek Wisata Alam Monkey Forest 2) Mendeskripsikan partisipasi masyarakat terhadap pengembangan ekowisata di Objek Wisata Alam Monkey Forest 3) Mendeskripsikan kontribusi dari kegiatan pariwisata di Monkey Forest terhadap masyarakat 4) Mengetahui kelayakan objek wisata alam Monkey Forest untuk pengembangan ekowisata. Metode penelitian yang digunakan dalam penelitian ini adalah metode observasi. Pengambilan sampel dengan teknik purposive sampling. Analisis data dilakukan dengan teknik analisis deskriptif kualitatif. Hasil penelitian menunjukkan, 1) Objek wisata Monkey Forest memiliki potensi wisata tergolong tinggi, 2) Partisipasi masyarakat yang tinggi dalam kegiatan pariwisata, 3) Kontribusi dari kegiatan pariwisata terhadap masyarakat lokal tergolong tinggi, dan 4) Kelayakan objek wisata alam Monkey Forest untuk pengembangan ekowisata memiliki tingkat kelayakan yang tinggi. Tingkat kelayakan yang tinggi disebabkan oleh indikatorindikator yang dimiliki tinggi.
\end{abstract}

Kata kunci: studi kelayakan, objek wisata, ekowisata

\begin{abstract}
The research was conducted in natural tourism object Monkey Forest with the aim 1) to describe the potential of ecotourism in natural tourism object Monkey Forest, 2) to describe the participation of ecotourism in natural tourism object Monkey Forest, 3) to describe contribution of ecotourism in natural tourism Monkey Forest, 4) to know level of feasibility tourism object for ecotourism development. Sampling by purposive sampling technique. Data was analyzed using qualitative descriptive analysis techniques. The results showed that 1) Tourism object Monkey Forest has ecotourism potential is high, 2) Participation of natural tourism object is high, 3) Contribution from tourism activities to local people is high, 4) and Monkey Forest feasibility for ecotourism development were high. The attraction Monkey Forest feasibility level to be developed as ecotourism were high, because all aspects of ecotourism already qualifies as ecotourism.
\end{abstract}

Keywords: feasibility study, attractions, ecotourism

\section{PENDAHULUAN}

Perencanaan

merupakan jalan untuk mewujudkan aspirasi dan tuntutan masyarakat. Salah satu usaha pembangunan yang dilakukan yaitu pada pengembangan industri pariwisata. Hal ini jelas terlihat dari banyaknya program pengembangan 
Kabupaten Gianyar Universitas Pendidikan Ganesha Jurusan Pendidikan Hukum dan Ilmu

Sosial (Volume x Tahun 2017)

kepariwisataan di berbagai Daerah Tujuan Wisata (DTW) di Indonesia. Alternatif pengembangan kepariwisataan adalah langkah yang sangat tepat, karena sektor pariwisata mampu menyediakan pertumbuhan ekonomi yang cepat dan mampu mengaktifkan sektor produksi lain atau akan membentuk suatu jaringan ekonomi lain dimana peluang-peluang yang ada diisi oleh para pelaku pada negara penerima wisatawan.

Bali sebagai salah satu daerah tujuan wisata utama di Indonesia, banyak memiliki potensi kepariwisataan yang bisa dikembangkan dan ditingkatkan. Kedudukan daerah Bali sudah dapat disejajarkan dengan daerah tujuan wisata lainnya yang ada di dunia. Hal ini dikarenakan keunikan budaya dan adat istiadatnya serta keindahan alam yang sangat menarik bagi wisatawan. Apalagi ditunjang dengan semakin bertambahnya dan berkembangnya sarana dan prasarana penunjang kepariwisataan, seperti: akomodasi, transportasi, fasilitas rekreasi dan hiburan, atraksi wisata, dan lainnya, serta sikap ramah tamah masyarakat dinilai mampu menarik wisatawan untuk datang dan memperpanjang lama tinggalnya.

Dapat disadari bahwa yang menjadi objek pariwisata di Bali adalah seluruh daerah Pulau Bali beserta seluruh tatanan kehidupan dan seni budayanya. Pengembangan pariwisata Bali harus disesuaikan dengan daya dukung yang dimiliki dan menetapkan sistem pembangunan kepariwisataan yang berkelanjutan agar lingkungan yang menjadi daya tarik utama dapat terjaga kelestariannya. Walaupun demikian, kesenjangan perkembangan pariwisata di Provinsi Bali masih tetap terjadi yaitu antara Bali bagian utara dengan Bali bagian selatan.

Pengembangan pariwisata harus merupakan pengembangan berencana secara menyeluruh, sehingga dimanfaatkan oleh masyarakat, baik segi ekonomi, sosial dan kultural, menghindari timbulnya permasalahan ekonomi, sosial dan kultural yang bersifat negatif. Perencanaan kepariwisataan harus mengintegrasikan pembangunan pariwisata menjadi suatu program pembangunan ekonomi, fisik, sosial, dimana semua itu harus mampu memberikan kerangka kerja kebijaksanan pemerintah untuk memotivasi dan mengendalikan pengembangan kepariwisataan. Wisata alternatif yang muncul sebagai reaksi terhadap dampak negatif yang ditimbulkan dari pengembangan dan perkembangan pariwisata adalah ekowisata (ecotourism).

Ekowisata merupakan kegiatan wisata yang bersifat khas yang mengandung tiga unsur "eko", yaitu 1) memperhatikan aspek ekologis, dimana kegiatan ekowisata mesti ramah lingkungan, 2) memperhatikan aspek ekonomis, kegiatan ini menguntungkan bagi masyarakat, terutama bagi masyarakat di sekitar kegiatan yang dilaksanakan, dan 3) memperhatikan persepsi masyarakat (Evaluating Community Optimum) yang mana kegiatan ini mesti memperhatikan pendapat dan melibatkan masyarakat lokal. Ekowisata (ecotourism) merupakan hal yang menciptakan dan memuaskan suatu keinginan akan alam, mengeksploitasi potensi wisata untuk konservasi dan pembangunan serta mencegah dampak negatifnya terhadap ekologi, kebudayaan dan keindahan (Western, 1995:3). Pilihan wisata alternatif mempunyai karakteristik seperti tingkat perkembangan yang relatif lambat dan terkontrol, mampu mengurangi dampak negatif yang ditimbulkan, pengambilan keputusan yang bersifat lokal dengan memperhatikan daya dukung yang dimiliki dan menerapkan pembangunan pariwisata yang berkelanjutan, sangat cocok dikembangkan di Bali yang memiliki lahan terbatas dan telah sesuai dengan konsep Tri Hita Karana yaitu menekankan pada keharmonisan hubungan antara manusia dengan Tuhan, manusia dengan manusia, dan manusia dengan lingkungannya.

Pada hakekatnya ekowisata yang melestarikan dan memanfaatkan alam serta budaya masyarakat, jauh lebih ketat dibandingkan dengan hanya keberlanjutan. Sebab ekowisata tidak melakukan eksploitasi alam tetapi hanya menggunakan jasa alam dan masyarakat untuk memenuhi kebutuhan pengetahuan 
e-Journal Studi Kelayakan Objek Wisata Alam Monkey Forest (Mandala Wisata Wenara Wana) untuk Pengembangan Ekowisata di Desa Padangtegal, Kecamatan Ubud,

Kabupaten Gianyar Universitas Pendidikan Ganesha Jurusan Pendidikan Hukum dan Ilmu

Sosial (Volume x Tahun 2017)

fisik, dan psikologis wisatawan. Bahkan dalam berbagai aspek ekowisata merupakan bentuk wisata yang mengarah ke metatourism. Ekowisata bukan menjual destinasi tetapi menjual filosofi. Dari aspek inilah ekowisata tidak akan mengenal kejenuhan pasar (Fandeli, 2000:8). Dengan demikian ekowisata dianggap tepat dikembangkan karena apresiasinya terhadap lingkungan, baik itu lingkungan alam maupun sosial budayanya.

Ekowisata dapat menjadi pengantar menuju pariwisata berkesinambungan karena di dalam ekowisata terdapat prinsip pembelajaran tentang alam dimana masyarakat turut mendapatkan manfaatnya (Pendit, 2002:149). Dengan ekowisata diharapkan dapat menjamin keberlangsungan hidup pariwisata tanpa harus mengorbankan lingkungan. Dari prinsip pembelajaran tentang alam dan manfaatnya terhadap masyarakat, maka Bali memiliki potensi besar dalam pengembangan ekowisata karena Bali termasuk Monkey Forest memiliki sejumlah sumber daya alam dan potensi sosial budaya berupa adat-istiadat masyarakat yang mampu menopang pembangunan pariwisata, bila semua sumber daya alam ini dikelola dengan baik akan dapat menunjang ekowisata, namun jika tidak ia akan menghancurkan bukan saja sektor pariwisata tetapi Bali secara keseluruhan.

\section{METODE}

Rancangan penelitian yang digunakan dalam penelitian ini adalah survai (Effendi dan Singarimbun, 1989), didukung dengan metode observasi secara langsung di lapangan, dan wawancara guna mengkaji potensi dan partisipasi masyarakat dalam pengembangan ekowisata. Pengambilan sampel dengan teknik purposive sampling. Analisis data dilakukan dengan teknik analisis kualitatif terhadap permasalahan penelitian.

Penelitian ini mengambil lokasi di Objek Wisata Monkey Forest yang terletak di Desa Padangtegal, Kecamatan Ubud, Kabupaten Gianyar.

Objek penelitian adalah potensi objek wisata alam Monkey Forest untuk pengembangan ekowisata Dengan memperhatikan objek tersebut, yang menjadi subjek penelitian adalah masyarakat Desa Padangtegal, pengelola, dan wisatawan objek wisata Monkey Forest yang selanjutnya akan dijadikan sebagai populasi.

Unit sampel penelitian berjumlah 50 diambil dengan cara mencari pihak yang terkait dengan penelitian. Aparat Desa Padangtegal 5, Pengelola objek wisata 20, dan pelaku usaha wisata 24 .

Pada Tabel 1 dapat dilihat definisi operasional variabel penelitian adalah potensi objek wisata, ekowisata dan partisipasi masyarakat. Kemudian Analisis data tersebut dilaksanakan dengan menggunakan metode analisis kualitatif secara deskriptif

Tabel 1. Variabel Penelitian

\begin{tabular}{|c|c|c|c|}
\hline No & Variabel & Parameter & Indikator \\
\hline (1) & (2) & (3) & (4) \\
\hline \multirow[t]{4}{*}{1} & \multirow{4}{*}{ Potensi wisata } & Atraksi wisata & Daya tarik utama \\
\hline & & Aksesibilitas & $\begin{array}{l}\text { - Kondisi jalan } \\
\text { - Jarak dari kota/kabupaten } \\
\text { - Transportasi } \\
\end{array}$ \\
\hline & & Fasilitas & $\begin{array}{l}\text { - } \text { Akomodasi } \\
\text { - Toko souvenir } \\
\text { - Restoran/rumah makan } \\
\end{array}$ \\
\hline & & Pelestarian lingkungan & $\begin{array}{l}\text { - } \text { Aturan (awig-awig) pelestarian } \\
\text { - } \text { Menjaga kebersihan } \\
\text { - } \text { Pengolahan limbah } \\
\end{array}$ \\
\hline 2 & Partisipasi masyarakat & Perencanaan & $\begin{array}{l}\text { Keterlibatan masyarakat dalam } \\
\text { - } \quad \text { Rapat-rapat } \\
\text { - Pengambilan keputusan } \\
\text { - } \text { Mengidentifikasi masalah }\end{array}$ \\
\hline
\end{tabular}


e-Journal Studi Kelayakan Objek Wisata Alam Monkey Forest (Mandala Wisata Wenara Wana) untuk Pengembangan Ekowisata di Desa Padangtegal, Kecamatan Ubud,

Kabupaten Gianyar Universitas Pendidikan Ganesha Jurusan Pendidikan Hukum dan Ilmu

Sosial (Volume x Tahun 2017)

\begin{tabular}{|c|c|c|c|}
\hline No & Variabel & Parameter & Indikator \\
\hline \multirow[t]{5}{*}{ (1) } & (2) & (3) & (4) \\
\hline & & & - Promosi \\
\hline & & Monitoring & $\begin{array}{l}\text { Keterlibatan masyarakat lokal dalam tim } \\
\text { monitoring/pengawas }\end{array}$ \\
\hline & & Pengelolaan & $\begin{array}{l}\text { Keterlibatan masyarakat lokal menjadi } \\
\text { - Petugas parkir } \\
\text { - Petugas keamanan } \\
\text { - Pemandu wisata } \\
\text { - Petugas kebersihan } \\
\text { - Petugas piket } \\
\text { - Pelatihan }\end{array}$ \\
\hline & & $\begin{array}{l}\text { Pengusaha/pelaku } \\
\text { ekonomi ekowisata }\end{array}$ & $\begin{array}{l}\text { - } \text { Akomodasi } \\
\text { - Jasa transportasi } \\
\text { - Restoran/rumah makan } \\
\text { - Souvenir/cendera mata } \\
\end{array}$ \\
\hline \multirow[t]{2}{*}{3} & \multirow{2}{*}{$\begin{array}{l}\text { Kontribusi dari kegiatan } \\
\text { pariwisata terhadap } \\
\text { masyarakat }\end{array}$} & Ekonomi & $\begin{array}{l}\text { - Pendapatan } \\
\text { - Peluang usaha/kesempatan kerja }\end{array}$ \\
\hline & & Fisik & $\begin{array}{l}\text { - Prasarana (jalan di kawasan objek wisata) } \\
\text { - Pengaturan tata ruang kawasan wisata } \\
\text { - } \text { Akomodasi } \\
\text { - } \text { Toko souvenir } \\
\text { Restoran/rumah makan }\end{array}$ \\
\hline
\end{tabular}

Sumber: Hasil Pengolahan Data Primer, 2017

\section{HASIL DAN PEMBAHASAN}

\section{Gambaran Umum Daerah Penelitian}

Tabel 2 merupakan pemaparan mengenai gambaran umum daerah penelitian ini dimaksudkan untuk mengetahui karakteristik daerah penelitian dan dalam pembahasan ini, gambaran umum penelitian akan ditinjau dari beberapa hal, yaitu: kondisi fisiografis dan kondisi demografis.

Tabel 2. Rekapitulasi Kondisi Fisik dan Demografi Desa Padangtegal

\begin{tabular}{|c|c|c|c|}
\hline No & $\begin{array}{l}\text { Kondisi Fisik } \\
\text { dan } \\
\text { Demografi }\end{array}$ & Hasil & Simpulan \\
\hline (1) & (2) & (3) & (4) \\
\hline \multirow[b]{2}{*}{1} & \multirow[b]{2}{*}{ Letak } & $\begin{array}{l}\text { Astronomis: 8030'50"'LU sampai } \\
8^{0} 51^{\prime} 38^{\prime \prime} \text { 'L dan } 115^{0} 15^{\prime} 50^{\prime \prime B T ~ s a m p a i ~} \\
115^{0} 26^{\prime} 38^{\prime \prime} B B\end{array}$ & \multirow[b]{2}{*}{$\begin{array}{l}\text { Posisinya berada di tengah-tengah Pulau } \\
\text { Bali }\end{array}$} \\
\hline & & $\begin{array}{l}\text { Geografis, berbatasan dengan: Utara; Br } \\
\text { Taman Kelod, Timur; Desa Peliatan, } \\
\text { Selatan; Desa Pengosekan; Banjar Ubud } \\
\text { Kelod. }\end{array}$ & \\
\hline 2 & Luas & ( & $\begin{array}{l}\text { Terdiri dari } 4 \text { banjar :Padangtegal Kaja, } \\
\text { Padang Kencana, Padangtegal Kelod, dan } \\
\text { Padangtegal Mekarsari. }\end{array}$ \\
\hline 3 & Geologi & $\begin{array}{l}\text { Disusun dari Tufa dan Endapan Lahar } \\
\text { Buyan-Bratan dan Batur. Jenis tanah } \\
\text { Regosol Coklat Kekuningan }\end{array}$ & $\begin{array}{l}\text { Menjadikannya wilayah Desa Padangtegal } \\
\text { menjadi subur. }\end{array}$ \\
\hline 4 & Topografi & $\begin{array}{l}\text { Dataran rendah dengan ketinggian rata- } \\
\text { rata } 325 \text { m dari permukaan air laut dengan } \\
\text { kemiringan lereng } 0-2 \%\end{array}$ & $\begin{array}{l}\text { Kemiringan wilayah yang tergolong datar } \\
\text { menyebabkan sebagaian besar lahan di } \\
\text { wilayah Desa Padangtegal memilliki } \\
\text { permukaan yang relatif datar }\end{array}$ \\
\hline 5 & Iklim & $\begin{array}{l}\text { Klasifikasi iklim W. Koppen : tergolong } \\
\text { kategori iklim A, iklim hujan tropis atau } \\
\text { topical rainway climate dengan tipe iklim } \\
\text { Am } \\
\text { Klasifikasi iklim Schmitd-Ferguson : } \\
\text { tergolong tipe iklim agak basah (C) }\end{array}$ & $\begin{array}{l}\text { Curah hujan rata-rata tahunannya adalah } \\
2327.2 \mathrm{~mm} \text {, sedangkan curah hujan bulan } \\
\text { terkering adalah } 56.2 \mathrm{~mm} \text { dan jatuh pada } \\
\text { bulan Agustus. }\end{array}$ \\
\hline 6 & Penggunaan & Penggunaan lahannya terdiri dari: Iahan & Berdasarkan data tersebut lahan yang ada \\
\hline
\end{tabular}


e-Journal Studi Kelayakan Objek Wisata Alam Monkey Forest (Mandala Wisata Wenara Wana) untuk Pengembangan Ekowisata di Desa Padangtegal, Kecamatan Ubud,

Kabupaten Gianyar Universitas Pendidikan Ganesha Jurusan Pendidikan Hukum dan Ilmu Sosial (Volume x Tahun 2017)

\begin{tabular}{c|c|l|l}
\hline No & $\begin{array}{c}\text { Kondisi Fisik } \\
\text { dan } \\
\text { Demografi }\end{array}$ & \multicolumn{1}{|c}{ Hasil } & \multicolumn{1}{c}{ Simpulan } \\
\hline$(1)$ & $(2)$ & \multicolumn{1}{|c}{$(3)$} & \multicolumn{1}{c}{ (4) } \\
\hline & Lahan & $\begin{array}{l}\text { persawahan 20 Ha, permukian 80 Ha, dan } \\
\text { lainnya 6 Ha. }\end{array}$ & $\begin{array}{l}\text { di Desa Padangtegal lebih banyak di } \\
\text { manfaatkan sebagai art shop, tempat } \\
\text { usaha, dan tempat tinggal. }\end{array}$ \\
\hline 7 & Demografi & $\begin{array}{l}\text { Jumlah penduduk tahun 2015 adalah 3711 } \\
\text { jiwa, yang terdiri dari laki-laki sebanyak } \\
\text { 1739 jiwa dan perempuan sebanyak 1973 } \\
\text { jiwa, Pertumbuhan penduduk sebanyak } \\
\text { 49\% per tahun, tergolong pada } \\
\text { pertumbuhan yang tinggi. Kepadatan } \\
\text { penduduk termasuk kedalam katagori } \\
\text { sangat padat, dimana tiap 1 km² adalah } \\
\text { 2719 jiwa. Komposisi penduduk menurut } \\
\text { pendidikan yang belum tamat SD 4,3\%, } \\
\text { tamat SD 6.3 \%, tamat SMP 4.9\%, tamat } \\
\text { SMA 6.3\% dan tamat PT 6.5\%. }\end{array}$ & $\begin{array}{l}\text { Kepadatan penduduk Desa Padangtegal } \\
\text { termasuk padat, dengan pertumbuhan } \\
\text { yang tinggi yang dikarenakan oleh dua } \\
\text { faktor, yaitu peningkatan angka kelahiran } \\
\text { dan adanya migrant masuk yang cukup } \\
\text { besar ke Desa Padangtegal. }\end{array}$ \\
\hline
\end{tabular}

Sumber: Hasil Pengolahan Data Primer, 2017

\section{Potensi Ekowisata pada Objek Wisata Alam Monkey Forest}

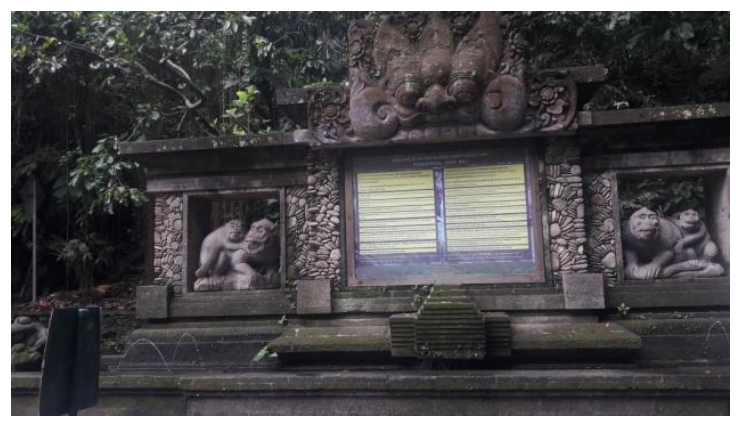

Gambar 1. Ikon Monkey Forest

Monkey Forest merupakan salah satu objek wisata alam di Kabupaten Gianyar. Dikatakan objek wisata alam karena daya tarik wisata dominan dari potensi alam dan hewan yaitu atraksi monyet ekor panjang dan pemandangan alamnya. Untuk mengukur tingkat kelayakan objek wisata untuk dikembangkan sebagai ekowisata akan dideskripsikan data hasil penelitian dan analisisnya.

Berdasarkan tabel 3 dari segi potensi wisata di objek wisata Monkey Forest dalam kategori tinggi. Hal ini dapat dilihat dari berbagai indikator yaitu dari aspek daya tarik utama dari wisata Monkey Forest yakni atraksi monyet ekor panjang di hutan, untuk dapat menikmati atraksi monyet ekor panjang ini dapat dilihat ketika kita berjalan-jalan melewati hutan atau bisa juga dilihat di stage ketika ada atraksi monyet sedang bergerombol. Sedangkan daya tarik pendukung kawasan wisata Monkey Forest yakni panorama yang indah dan udara segar yang cukup menjadikan daya tarik tersendiri bagi wisatawan untuk berdatangan ke daerah wisata Monkey Forest.

Tabel 3. Potensi Wisata di Monkey Forest

\begin{tabular}{|c|c|c|c|c|}
\hline No & Potensi & Indikator & Skor & Kriteria \\
\hline \multirow[t]{2}{*}{1} & \multirow[t]{2}{*}{ Atraksi Wisata } & Daya tarik utama & 3 & Ada dan dilestarikan \\
\hline & & Daya tarik pendukung & 3 & Ada dan dilestarikan \\
\hline \multirow[t]{3}{*}{2} & \multirow[t]{3}{*}{ Aksesbilitas } & Kondisi Jalan & 3 & Baik (tidak berlubang dan retak) \\
\hline & & Jarak dari kota/kabupaten & 1 & Sangat Jauh $>10 \mathrm{Km}$ \\
\hline & & Transportasi & 1 & Tidak ada \\
\hline \multirow[t]{4}{*}{3} & \multirow[t]{4}{*}{ Fasilitas } & Akomodasi & 3 & Banyak \\
\hline & & Rumah makan/minum & 3 & Banyak \\
\hline & & Toko souvenir & 3 & Banyak \\
\hline & & Pos kesehatan & 3 & Ada dan beroperasi \\
\hline 4 & Kelembagaan & Pos keamanan & 1 & Tidak ada \\
\hline
\end{tabular}


e-Journal Studi Kelayakan Objek Wisata Alam Monkey Forest (Mandala Wisata Wenara Wana) untuk Pengembangan Ekowisata di Desa Padangtegal, Kecamatan Ubud,

Kabupaten Gianyar Universitas Pendidikan Ganesha Jurusan Pendidikan Hukum dan Ilmu

Sosial (Volume x Tahun 2017)

\begin{tabular}{|c|c|c|c|c|}
\hline & & Pusat informasi & 3 & Ada dan beroperasi \\
\hline & & Pengelola & 3 & Desa adat \\
\hline & & Struktur Organisasi & 3 & Ada sesuai standar manajemen \\
\hline \multirow[t]{3}{*}{5} & \multirow{3}{*}{$\begin{array}{l}\text { Pelestarian } \\
\text { Lingkungan }\end{array}$} & Aturan (awig-awig) pelestarian & 3 & Ada dan dilaksanakan \\
\hline & & Menjaga kebersihan & 3 & Rutin (terjadwal) \\
\hline & & Pengolahan Limbah & 3 & Ada \\
\hline \multicolumn{3}{|c|}{ Sub Total (kategori) } & 44 & (potensi tinggi) \\
\hline
\end{tabular}

Sumber: Hasil Pengolahan Data Primer, 2017

Dari beberapa daya tarik yang dimiliki, objek wisata Monkey Forest tidak mengesampingkan aktivitas religius, terbukti dengan adanya Pura Dalem Agung, Pura yang terdapat di tengahtengah Monkey Forest juga merupakan salah satu daya tarik pendukung. Pura Dalem ini juga sering dikunjungi oleh umat Hindu saat perayaan upacara agama seperti melasti dan odalan. Monkey Forest sendiri yang terletak sekitar 11 kilometer sebelah barat Kota Gianyar. Sementara dari Kota Denpasar Monkey Forest berjarak sekitar 24 kilometer sebelah timur. Kondisi jalan dari ibu kota kabupaten cukup baik. Transportasi khusus juga disediakan oleh hotel-hotel di sekitar kawasan wisata Monkey Forest. Sedangkan transportasi umum seperti angkutan yang tersedia untuk menuju Monkey Forest terbilang banyak walaupun aksesibilitasnya terbilang bukan jalan utama.

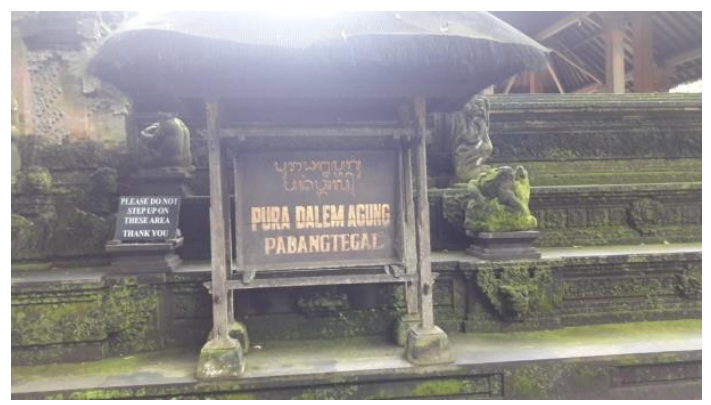

Gambar 2. Pura Dalem Agung Padangtegal

Fasilitas untuk akomodasi seperti hotel dan penginapan, tersebar di pinggiran jalan dari luar gerbang Monkey Forest tersebar sampai di sekitar jalan menuju Monkey Forest. Hotel atau penginapan yang ditawarkan juga dalam bentuk berbagai macam dengan fasilitasnya yang memadai. Rumah makan tersedia cukup banyak baik di sekitaran Monkey Forest maupun disekitar jalan menuju Monkey Forest itu sendiri. Terdapat pula toko-toko souvenir yang menjual berbagai macam barang dagangan antara lain pakaian khas Bali aksesoris dan lain sebagainya. Pos kesehatan selalu beroperasi baik pagi maupun sore hari. Untuk dijaga oleh dokter umum dan perawat, dan untuk sore harinya dijaga oleh ahli madya. Terdapat pula pusat informasi yang selalu beroperasi di Monkey Forest yang salah satunya menawarkan jasa pemandu wisata atau guide untuk di daerah objek wisata Monkey Forest.

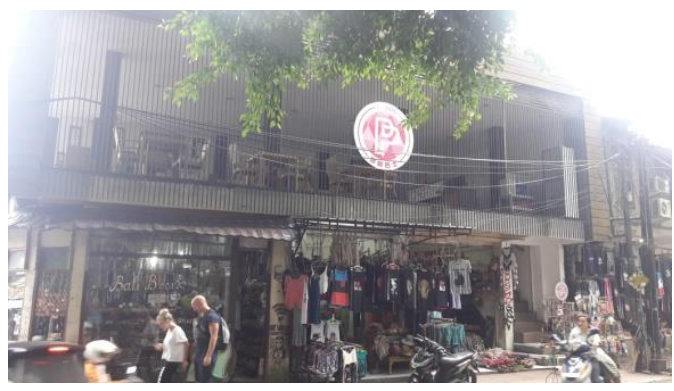

Gambar 3. Restoran dan Toko Souvenir

Dalam pelestarian lingkungan, seperti desa adat lain di Bali, Desa Adat Padangtegal juga menerapkan awig-awig. Seperti melakukan kegiatan pembersihan tiap sebulan sekali di sekitar areal Pura Dalem Agung Padangtegal, disamping dilakukan oleh petugas kebersihan yang melakukan setiap harinya. Sedangkan untuk pengolahan limbah, dilakukan pembuangan sampah organik di sekitar pinggiran hutan, dan untuk sampah non organik di buang ke tempat pembuangan akhir. Untuk masing-masing pelaku usaha wisata sudah melaksanakan pengolahan limbahnya sendiri.

\section{Partisipasi Masyarakat Terhadap Pengembangan Ekowisata di Objek Wisata Monkey Forest}


e-Journal Studi Kelayakan Objek Wisata Alam Monkey Forest (Mandala Wisata Wenara Wana) untuk Pengembangan Ekowisata di Desa Padangtegal, Kecamatan Ubud,

Kabupaten Gianyar Universitas Pendidikan Ganesha Jurusan Pendidikan Hukum dan Ilmu

Berdasarkan tabel 4 dari segi partisipasi masyarakat di objek wisata Monkey Forest termasuk partisipasi tinggi. Partisipasi masyarakat dalam pengembangan ekowisata di Monkey Forest sangat penting. Pihak pengelola
Sosial (Volume x Tahun 2017) melibatkan masyarakat lokal yang bekerja di tempat wisata tersebut serta masyarakat lokal yang tinggal di Desa Padangtegal. Masyarakat lokal ikut berpartisipasi dalam pengambilan keputusan.

Tabel 4. Partisipasi Masyarakat Lokal dalam Pengembangan Ekowisata Monkey Forest

\begin{tabular}{|c|c|c|c|c|}
\hline No & Potensi Wisata & Indikator & Skor & Kriteria \\
\hline (1) & (2) & (3) & (4) & (5) \\
\hline \multirow[t]{4}{*}{1} & \multirow[t]{4}{*}{ Perencanaan } & Rapat-rapat & 2 & Kadang-kadang dilibatkan \\
\hline & & Pengambilan keputusan & 3 & Selalu dilibatkan \\
\hline & & Mengindentifikasi & 2 & Kadang-kadang dilibatkan \\
\hline & & Promosi wisata & 3 & Selalu dilibatkan \\
\hline 2 & Monitoring & Tim & 3 & Selalu dilibatkan \\
\hline \multirow[t]{5}{*}{3} & \multirow[t]{5}{*}{ Pengelolaan } & Petugas parkir & 3 & Selalu dilibatkan \\
\hline & & Petugas keamanan & 3 & Selalu dilibatkan \\
\hline & & Pemandu wisata & 3 & Selalu dilibatkan \\
\hline & & Petugas kebersihan & 3 & Selalu dilibatkan \\
\hline & & Karyawan & 3 & Selalu dilibatkan \\
\hline \multirow[t]{4}{*}{4} & \multirow{4}{*}{$\begin{array}{l}\text { Pengusaha/ pelaku } \\
\text { ekonomi ekowisata }\end{array}$} & Akomodasi & 3 & Selalu dilibatkan \\
\hline & & Jasa transportasi & 3 & Selalu dilibatkan \\
\hline & & Restoran/ rumah makan & 3 & Selalu dilibatkan \\
\hline & & Souvenir/ cendera mata & 3 & Selalu dilibatkan \\
\hline \multicolumn{3}{|c|}{ Sub Total (kategori) } & 40 & (partisipasi tinggi) \\
\hline
\end{tabular}

Sumber: Hasil Pengolahan Data Primer, 2017

Partisipasi masyarakat lokal dari segi monitoring yaitu melihat dari kesiapan pemantauan baik keamanan, ketertiban maupun kelancaran jalannya suatu kepariwisataan di Monkey Forest. Selain itu melibatkan berbagai pihak seperti petugas parkir, petugas keamanan (pecalang), pemandu wisata (guide), dan petugas kebersihan. Petugas parkir yang ditugaskan untuk menjaga ketertiban parkir di kawasan Monkey Forest. Partisipasi masyarakat lokal sangat diperlukan dalam proses pembangunan dan pengembangan Monkey Forest sehingga Monkey Forest dapat menjadi kawasan ekowisata.

Petugas keamanan yang bertugas menjaga keamanan Monkey Forest adalah beberapa orang yang berasal dari Desa Padangtegal. Masyarakat lokal juga dilibatkan sebagai pemandu wisata atau guide untuk. Mempermudah wisatawan dalam memperoleh informasi yang berkaitan dengan objek di sekitar Monkey Forest. Pemandu wisata tersebut berkerja sama dengan pihak hotel untuk memberikan jasa antar- jemput, sarana penunjang dalam perjalanan, dan fasilitas yang mengutamakan kenyamanan wisatawan.
Terdapat pula petugas kebersihan yang selalu rutin membersihkan wilayah di sekitar Monkey Forest. Petugas kebersihan tersebut, selalu dilibatkan dalam menjaga kebersihan dan terdapat jadwal pada pagi dan sore hari yang dilaksanakan oleh pihak masyarakat dan pengelola setempat.

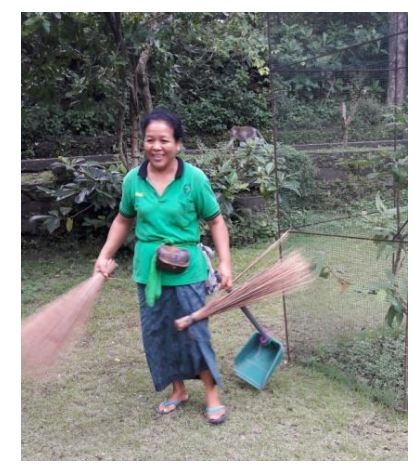

Gambar 4. Petugas Kebersihan

Partisipasi masyarakat lokal yang keempat yaitu pada pengusaha/pelaku ekonomi ekowisata yang terdapat pada akomodasi masyarakat terlihat dari adanya kerjasama dari pihak pengelolaan dengan pihak hotel-hotel yang terdapat di kawasan wisata Monkey Forest. Pihak hotel 
e-Journal Studi Kelayakan Objek Wisata Alam Monkey Forest (Mandala Wisata Wenara Wana) untuk Pengembangan Ekowisata di Desa Padangtegal, Kecamatan Ubud,

Kabupaten Gianyar Universitas Pendidikan Ganesha Jurusan Pendidikan Hukum dan Ilmu Sosial (Volume x Tahun 2017)

menyediakan fasilitas penunjang dan pihak memberi informasi dari ketersediaan hotel yang akan menjamin kenyamanan wisatawan. Jasa transportasi yang terdapat di Monkey Forest selalu dilibatkan dengan adanya mobil transport yang disediakan oleh pihak hotel kawasan wisata Monkey Forest.

Pelaku usaha seperti usaha rumah makanan selalu dilibatkan baik yang terdapat di luar dan di dalam kawasan wisata Monkey Forest. Beberapa masyarakat setempat memanfaatkan pembangunan restoran di wilayah Monkey Forest dengan terstruktur, sehingga dapat seimbang antara tempat terdapatnya restoran dengan artshop yang ada. Salah satu rumah makan yang terdapat di dalam kawasan wisata Monkey Forest adalah "Bebek Bengil". Souvenir/cendera mata yang terdapat selalu dilibatkan dengan memanfaatkan tata ruang yang ada. Pekerja atau pegawai yang menjaga toko souvenir/ cenderamata tersebut berasal dari warga desa setempat sebagai peluang bagi masyarakat yang dijadikan mata pencaharian sehari-harinya.

\section{Kontribusi dari Kegiatan Pariwisata di Objek Wisata Monkey Forest terhadap Masyarakat Lokal}

Berdasarkan tabel 5 dari segi kontribusi dari kegiatan pariwisata terhadap masyarakat lokal Desa Padangtegal dalam kategori kontribusi tinggi. Hal ini dapat dilihat dari berbagai indikator yaitu kegiatan pariwisata di Monkey Forest mempengaruhi sosial ekonomi masyarakat lokal, seperti bertambahnya pendapatan masyarakat yang bekerja disana. Pendapatan pedagang akan bertambah cukup signifikan pada bulan Juli hingga Agustus pada saat akhir semester dan kenaikan kelas karena wisatawan lokal maupun mancanegara banyak yang melakukan kegiatan wisata khususnya untuk berlibur. Prasarana seperti jalan yang ada di Monkey Forest sebagian berada dalam kondisi baik, sehingga tidak mengganggu aktivitas wisatawan.

Tabel 5. Kontribusi dari Kegiatan Pariwisata Terhadap Masyarakat Lokal

\begin{tabular}{|c|c|c|c|c|}
\hline No & Potensi & $\begin{array}{r}\text { Indikator } \\
\end{array}$ & Skor & Kriteria \\
\hline \multirow[t]{3}{*}{1} & \multirow[t]{3}{*}{ Sosial ekonomi } & Peningkatan pendapatan & 2 & Kadang-kadang \\
\hline & & Kesempatan kerja & 2 & Ada dengan syarat ketat \\
\hline & & Prasarana (jalan di kawasan objek) & 3 & Kondisi bagus (lebar dan tidak rusak) \\
\hline \multirow[t]{4}{*}{2} & \multirow[t]{4}{*}{ Fisik } & Pengaturan tata ruang kawasan & 3 & Ada dan teratur \\
\hline & & Akomodasi & 3 & Banyak $>1$ \\
\hline & & Toko souvenir & 3 & Banyak >1 \\
\hline & & Restoran/rumah makan & 3 & Banyak >1 \\
\hline \multicolumn{3}{|c|}{ Sub Total (kategori) } & 19 & (kontribusi tinggi) \\
\hline
\end{tabular}

Sumber: Hasil Pengolahan Data Primer, 2017

Kegiatan pariwisata di Monkey forest secara fisik juga memberikan kontribusi kepada masyarakat lokal. Pengaturan tata ruang yang teratur membuat banyak pelaku usaha ekonomi wisata yang bekerja di Monkey Forest. Setiap tempat wisata tentu memiliki akomodasi dan restoran atau rumah makan yang jumlahnya lebih dari satu sehingga membutuhkan banyak tenaga kerja. Tenaga kerja tersebut dapat diambil dari masyarakat lokal yang berada di sekitar Monkey Forest. Disediakannya tempat untuk berjualan souvenir oleh desa adat yang jumlahnya lebih dari satu membuka peluang bagi masyarakat lokal untuk berjualan di tempat tersebut. Hal ini dapat menambah penghasilan masyarakat. Oleh karena itu, tempat wisata memberikan kontribusi tinggi terutama dalam bidang ekonomi kepada masyarakat lokal.

Dari uraian diatas, ketiga aspek ekowisata baik itu potensi wisata, partisipasi terhadap masyarakat lokal khususnya masyarakat di sekitar objek wisata, dan kontribusi dari kegiatan pariwisata terhadap masyarakat lokal menunjukkan kategori yang tinggi terkait dengan potensi ekowisata. Hal ini akan berpengaruh pada tingkat kelayakan objek 
e-Journal Studi Kelayakan Objek Wisata Alam Monkey Forest (Mandala Wisata Wenara Wana) untuk Pengembangan Ekowisata di Desa Padangtegal, Kecamatan Ubud,

Kabupaten Gianyar Universitas Pendidikan Ganesha Jurusan Pendidikan Hukum dan Ilmu Sosial (Volume x Tahun 2017)

wisata untuk dikembangkan sebagai ekowisata.

\section{Kelayakan Objek Wisata Alam Monkey Forest untuk Pengembangan Ekowisata}

Tabel 6 Menunjukkan tingkat kelayakan ekowisata tergolong tinggi. Hal ini karena aspek pada masing-masing ekowisata menunjukkan potensi tinggi, seperti pada aspek potensi wisata dengan kategori potensi tinggi, aspek partisipasi masyarakat dengan kategori tinggi, dan aspek kontribusi pariwisata terhadap masyarakat lokal juga kategori tinggi. Dari semua aspek tersebut akan berpengaruh pada potensi ekowisata di objek wisata Monkey Forest termasuk memiliki tingkat kelayakan kategori tinggi untuk pengembangan ekowisata.

Tabel 6. Tingkat Kelayakan Objek Wisata Untuk Pengembangan Ekowisata

\begin{tabular}{c|c|c|c|c|c}
\hline \multirow{2}{*}{ No } & Objek Wisata & \multicolumn{3}{|c|}{ Aspek Ekowisata } & $\begin{array}{c}\text { Tingkat } \\
\text { Kelayakan } \\
\text { Ekowisata }\end{array}$ \\
\cline { 3 - 5 } & Potensi Wisata & $\begin{array}{c}\text { Partisipasi } \\
\text { Masyarakat }\end{array}$ & $\begin{array}{c}\text { Kontribusi Terhadap } \\
\text { Masyarakat Lokal }\end{array}$ & $(5)$ & $(6)$ \\
\hline$(1)$ & $(2)$ & $(3)$ & $(4)$ & 19 & 103 (tinggi) \\
\hline 1 & Monkey Forest & 44 & 40 & 19 & (2)
\end{tabular}

Sumber: Hasil Pengolahan Data Primer, 2017

$\begin{array}{lcr}\text { Banyak hal yang perlu diperbaiki } \\ \text { agar sesuai } & \text { dengan syarat dari } \\ \text { pengembangan } & \text { ekowisata, mulai dari } \\ \text { pengembangan } & \text { potensi }\end{array}$ meningkatkan partisipasi masyarakat yang tidak hanya pemilik lahan saja sehingga dapat membuka peluang usaha lebih luas dan dapat meningkatkan pendapatan masyarakat di sekitar kawasan wisata.

\section{PENUTUP \\ Simpulan}

Berdasarkan penyajian data, hasil, dan pembahasan yang telah diuraikan di atas, maka dapat ditarik simpulan sebagai berikut: (1) Pada kawasan objek wisata alam Monkey Forest potensi ekowisata yang dimiliki dari atraksi wisata, aksesbilitas, fasilitas, kelembagaan, dan aspek pelestarian memiliki kriteria yang tinggi yang mampu membuat wisatawan menjadi tertarik untuk berwisata ke objek wisata ini. Selain daya tarik utama atraksi dari monyet ekor panjang, daya pendukungnya juga menjadi perhatian bagi wisatawan. (2) Partisipasi masyarakat terhadap pengembangan ekowisata di objek wisata alam Monkey Forest dikategorikan tinggi, terlihat dari masyarakat desa yang ikut serta dalam pengambilan keputusan, bahkan dari pengelolaan objek wisata masyarakat desalah yang bekerja di Monkey Forest. (3) Kontribusi dari kegiatan pariwisata di Monkey Forest terhadap masyarakat lokal berkontribusi tinggi, seperti masyarakat desa yang diutamakan sebagai pengelola, dimana syarat yang diberikan untuk masyarakat tidaklah terlalu berat untuk dilakukan. Peningkatan pendapatan yang dimiliki juga terjadi, walaupun tidak terlalu signifikan. (4) Potensi ekowisata yang tinggi, partisipasi masyarakat yang tinggi, serta kontribusi dari kegiatan pariwisata terhadap masyarakat lokal yang tinggi menjadikan kelayakan objek wisata Monkey Forest sebagai pengembangan ekowisata memiliki kelayakan yang tinggi.

\section{Saran}

Berdasarkan pada hasil penelitian, pembahasan, dan simpulan, maka dapat diajukan saran sebagai berikut: (1) Bagi penelitian sejenis, hasil dari penelitian ini diharapkan dapat berguna bagi penelitian sejenis, yaitu dapat menambah wawasan serta dapat dijadikan bahan acuan atau referensi dalam penelitian selanjutnya. (2) Bagi pemerintah, hasil dari penelitian ini diharapkan mampu dijadikan sebagai informasi dan pertimbangan untuk mengembangkan sebuah objek wisata sebagai ekowisata. (3) Bagi masyarakat, hasil dari penelitian ini diharapkan agar masyarakat dan pengelola objek wisata dapat bekerja sama dengan baik, baik dari segi partisipasi dari perencanaan, pengelolaan, dan monitoring pada objek 
e-Journal Studi Kelayakan Objek Wisata Alam Monkey Forest (Mandala Wisata Wenara Wana) untuk Pengembangan Ekowisata di Desa Padangtegal, Kecamatan Ubud,

Kabupaten Gianyar Universitas Pendidikan Ganesha Jurusan Pendidikan Hukum dan Ilmu Sosial (Volume x Tahun 2017)

wisata yang dimiliki agar dapat memberikan kontribusi terhadap masyarakat lokal. Khususnya bagi masyarakat Desa Padangtegal diharapkan agar tetap berpartisipasi pada pengembangan ekowisata.

\section{DAFTAR PUSTAKA}

Achmad, Amran, dkk.2012. Identifikasi Tutupan Vegetasi Dan Potensi Fisik Lahan Untuk Pengembangan Ekowisata Di Laboratorium Lapangan Konservasi Sumberdaya Hutan Dan Ekowisata Hutan Pendidikan UNHAS. Jurnal Penelitian Kehutanan Wallacea Vol.1 No.2, Desember 2012 : 87-102

Andayani, N.L. Henny dan N.Nym. Yulianthini. 2013. Pengembangan Selancar (surfing) di Kawasan Wisata pantai Kuta, Kabupaten Badung melalui pemberdayaan masyarakat (community based development). Jurnal IImiah. Media Komunikasi FIS Vol.12, No.1, April 2013

Astiti, Dewi. 2003. Penerapan Tri Hita Karana dalam Pengembangan Ekowisata pada Waka Gangga Resort Tabanan. Tugas Akhir (tidak diterbitkan). Program Studi Pariwisata Universitas Udayana.

\section{Baiquni, M. 2010. Pariwisata Berkelanjutan dalam Pusaran Krisis Global. Denpasar: Udayana University Press.}

Fandeli, Chafid dan Muklison. 2000. Pengusahaan Ekowisata.Yogyakarta: Fakultas Kehutanan UGM.

Kawi, Gede. 2003. "Prospek dan Kendala serta Pendidikan Lingkungan Ekowisata Tanam Nasional Bali Barat Menurut perspektif Geografi". Makalah disajikan dalam Pertemuan IImiah Tahunan (PIT) lkatan Geografi Indonesia (IGI). IKIP Negeri Singaraja, Lovina 17-18 Oktober 2003 (tidak diterbitkan).
Kertasapoetra, A. 2004. Klimatologi Pengaruh Iklim Terhadap Tanah dan Tanaman. Jakarta: Bina Aksara.

Mantra, Ida Bagus. 1985. Pengantar Studi Demografi. Yogyakarta: Nurcahaya.

Nugroho, Iwan. 2011. Ekowisata dan Pembangunan Berkelanjutan. Yogyakarta: Pustaka Pelajar.

Page, Stephen J and Rose K Dowling. 2001. Ecotourism. London: Prentice Hall.

Pendit. 2002. IImu Pariwisata Sebuah Pengantar Perdana. Jakarta : Pradnya Paramitha.

Sanjaya, Ade. 2015. Landasan Teori. http//landasanteori.com/2015/10/peng ertian-pariwisata-definisi-jenis.html. (Diakses 15/06/2017).

Satria, Dias. 2009. Strategi Pengembangan Ekowisata Berbasis Ekonomi Lokal Dalam Rangka Program Pengentasan Kemiskinan Di Wilayah Kabupaten Malang. Journal of Indonesian Applied Economics. Vol. 3 No. 1 Mei 2009, 37-47.

Sujali. 1989. Geografi Pariwisata Dan Kepariwisataan. Yogyakarta: Fakultas Geografi UGM.

Sutikno. 2003. Penulisan Laporan Penelitian untuk Pertemuan IImiah. Ikatan Geografi Indonesia. Makalah disampaikan dalam PIT IGI ke-5 di Bali Taman Lovina Resort tanggal 1718 Oktober 2004. (tidak diterbitkan).

Supartha, Wayan. 1999. Bali dan Masa Depannya. Denpasar: Balai Pustaka.

Surpha, I Wayan. 1993. Eksistensi Desa Adat Di Bali Dengan Diundangkannya Undang-Undang No. 5 Tahun 1979 (Tentang Pemerintah Desa). Denpasar: Upada Sastra.

Western, David. 1995. Ekoturisme: Petunjuk Untuk Perencanaan \& 
e-Journal Studi Kelayakan Objek Wisata Alam Monkey Forest (Mandala Wisata Wenara Wana) untuk Pengembangan Ekowisata di Desa Padangtegal, Kecamatan Ubud, Kabupaten Gianyar Universitas Pendidikan Ganesha Jurusan Pendidikan Hukum dan Ilmu Pengelolaan. Jakarta: The Ecotourism Society North Benington, Vermont.

Yoeti, O. A. 2000 Ekowisata Pariwisata Berwawasan Lingkungan. P.T. Pertja: Jakarta

$\begin{array}{ccr}\text { Yunus, Hadi } & \text { Sabari. } & 2010 . \\ \text { Metodologi } & \text { Penelitian } & \text { Wilayah } \\ \text { Kontemporer. } & \text { Yogyakarta: } & \text { Pelajar } \\ \text { Pustaka. } & & \end{array}$

